\title{
Amelioration of Rheumatoid Arthritis by Anacardium occidentale via Inhibition of Collagenase and Lysosomal Enzymes
}

\author{
Rabiya Naz, ${ }^{1}$ Zaheer Ahmed $\left(\mathbb{D},{ }^{2}\right.$ Muhammad Shahzad, ${ }^{3}$ Arham Shabbir $\left(\mathbb{D},{ }^{4}\right.$ \\ and Faiza Kamal ${ }^{1}$ \\ ${ }^{1}$ Department of Home and Health Sciences, Allama Iqbal Open University Islamabad, Islamabad, Pakistan \\ ${ }^{2}$ Department of Environmental Design, Health and Nutritional Sciences, Allama Iqbal Open University Islamabad, \\ Islamabad, Pakistan \\ ${ }^{3}$ Department of Pharmacology, University of Health Sciences Lahore, Lahore, Pakistan \\ ${ }^{4}$ Institute of Pharmacy, Faculty of Pharmaceutical and Allied Health Sciences, Lahore College for Women University, Jail Road, \\ Lahore, Pakistan
}

Correspondence should be addressed to Zaheer Ahmed; zaheer863@gmail.com

Received 25 August 2020; Revised 9 October 2020; Accepted 19 October 2020; Published 9 November 2020

Academic Editor: Francesca Mancianti

Copyright (c) 2020 Rabiya Naz et al. This is an open access article distributed under the Creative Commons Attribution License, which permits unrestricted use, distribution, and reproduction in any medium, provided the original work is properly cited.

\begin{abstract}
Anacardium occidentale (cashew) has been used in the traditional system of medicine for curing many inflammatory disorders. The present study investigates the antiarthritic effects of cashew leaves extract using the rat model of FCA-induced rheumatoid arthritis. Arthritic rats were treated with 100 and $200 \mathrm{mg} / \mathrm{kg}$ b.w. ethanolic extract of cashew leaves. Animals were sacrificed at day 23 , and before sacrificing the animals, gross pathological changes were observed. Histopathology of ankle joint was evaluated with hematoxylin and eosin staining, whereas the serum levels of C-reactive protein (CRP) were evaluated by the agglutination method. Inflammatory cells and other hematological parameters were assessed by employing an automated hemocytometer and chemistry analyzer. Rheumatoid factor (Rf) and lysosomal enzymes levels were determined in blood. Results indicated that A. occidentale significantly decreased the CPR levels, macroscopic arthritic score, and rheumatoid factor as compared to the diseased group. Histopathological evaluation showed significant attenuation in bone erosion, joint inflammation, and pannus formation by plant extract. Treatment with $A$. occidentale significantly suppressed the levels of acid phosphatase, $\beta$-galactosidase, $\beta$-glucuronidase, $N$ acetylglucosaminidase, and collagenase. Moreover, A. occidentale significantly raised the HB levels and RBCs counts which were found depleted in the diseased group. The raised counts of total leukocytes, platelets, neutrophils, lymphocytes, and monocytes were also significantly decreased by treatment with plant extract. Comparative analysis showed that higher dose of A. occidentale demonstrated superior amelioration of rheumatoid arthritis as compared to low dose. In conclusion, A. occidentale possesses significant antiarthritic potential, which may be attributed to the suppression of lysosomal enzymes and collagenase levels.
\end{abstract}

\section{Introduction}

Rheumatoid arthritis is an autoimmune disease that affects the joints but can also involve various extra-articular complications. It affects almost every diarthrodial joint and the hallmark features include persistent chronic inflammation, pannus formation, cartilage/bone erosion, and synovial proliferation. Extra-articular manifestations may implicate weight loss, rheumatoid nodules, vasculitis, serositis, etc. [1-3]. Globally, $1 \%$ of the population suffers from the rheumatoid arthritis and the age between 35 and 45 years is considered as the peak age for the onset of disease. RA significantly affects the quality of life causing elevation in functional and work disability, morbidity rate, and economic burden [4-6].

Conventional medicines currently in use for arthritic treatment, such as disease-modifying antirheumatic agents, NSAIDs, steroids, and biological agents, have only limited success against RA and are linked with numerous side effects $[7,8]$. Long-term use of these therapies is associated with well-known limitations like risks of hematological, gastrointestinal, cardiovascular, and kidney disorders and loss of response [9]. Plant-based medicines are gaining prime importance among patients suffering from RA due to the adverse effects associated with conventional therapy $[10,11]$. 
Anacardium occidentale L. (Family: Anacardiaceae) has been traditionally used for curing many inflammatory diseases [12]. Previous studies have shown anti-inflammatory effects of $A$. occidentale in different models of inflammation. It is known to inhibit carrageenan-induced paw edema and formalin-induced paw licking in rats [13]. Treatment with $A$. occidentale also reduced ear edema and impaired leukocyte migration into the peritoneal cavity when tested using carrageenan-induced peritonitis [14]. Methanolic extract of $A$. occidentale showed protection against lipopolysaccharide-induced microvascular permeability $[15,16]$. Treatment with $A$. occidentale significantly reduced prostaglandin-E2 production in the microglia. The plant showed anti-inflammatory property by inhibiting inflammation-associated cytokine production. Moreover, significant inhibition of COX-2 and iNOS gene production by blocking MAPK and NF- $\kappa$ B pathways were observed [16]. The current study aimed to evaluate the antiarthritic effects of Anacardium occidentale using FCA-induced rat model of arthritis.

\section{Materials and Methods}

2.1. Experimental Animals. Male Wistar rats of age 6 to 8 weeks, weighing 225-250 g, were retained at standard conditions in animal house of the University of Punjab, Lahore. Animals were given distilled water and standard rat chow ad libitum. After development of arthritis, food was given on the lower portion of the cages as severely arthritic rats have problem in taking feed from the upper half of the cage. Standard temperature and humidity conditions (24-26 ${ }^{\circ} \mathrm{C}$ and $40-60 \%$, resp.) were maintained [17]. All the experiments and protocols were approved by the Allama Iqbal Open University, Islamabad (AIOU/283).

2.2. Preparation of Plant Extract. The leaves of the Anacardium occidentale were collected, identified by the Botanist, and shade-dried at room temperature. The leaves were ground to powdered form (yielding $300 \mathrm{~g}$ ) and the powdered sample was macerated in $2 \mathrm{~L}$ of ethanol at room temperature for $24 \mathrm{~h}$. Filtrate was collected by passing the mixture through muslin cloth and subsequently through filter paper (Whatman No. 1). The residue left was again macerated in ethanol and the procedure was repeated 3 times for the collection of filtrates. The resultant filtrate was evaporated in water bath (maintained at $40^{\circ} \mathrm{C}$ ) to obtain a semisolid extract. The percentage yield was calculated as $6.67 \%$. The extract was then kept in a refrigerator at $4^{\circ} \mathrm{C}$ for further use.

2.3. Experimental Design and Induction of Arthritis. Rats were distributed into 5 groups, having 6 rats in each group.

Group 1 (control): it included healthy rats serving as control group, injected with $0.1 \mathrm{ml}$ normal saline at the subplantar region in hind paw.

Group 2 (arthritic): Freund's Complete Adjuvant (FCA) was used to induce arthritis. Normal saline was administered to this group from day 8, once daily for 15 days.

Group 3 (AO $100 \mathrm{mg} / \mathrm{kg}$ ): it included arthritic rats receiving low oral dose of Anacardium occidentale extract, i.e., $100 \mathrm{mg} / \mathrm{kg}$ b.w. Treatment was started from day 8 , once daily for 15 days.

Group 4 (AO $200 \mathrm{mg} / \mathrm{kg}$ ): arthritic rats were given high oral dose of Anacardium occidentale extract, i.e., $200 \mathrm{mg} / \mathrm{kg}$ b.w. Treatment was started from day 8 , once daily for 15 days.

Group 5 (piroxicam): arthritic rats received $10 \mathrm{mg} / \mathrm{kg}$ b.w. piroxicam as standard drug [18]. Treatment was started from day 8, once daily intraperitoneally for 15 days.

For the induction of arthritis, $0.2 \mathrm{ml} \mathrm{FCA} \mathrm{(a} \mathrm{suspension}$ of heat-killed Mycobacterium) was injected in the subplantar region of the left hind rat paw on day 0 in all groups except control group. Treatment was started at the 8th day of arthritis induction for 15 days and all animals were sacrificed at day 23 [18].

2.4. Determination of Arthritic Development. Incidence and severity of arthritis was evaluated by arthritic scoring method. Presence of the detectable clinical arthritic features characterized by edema and/or erythema in the hind rat paws was observed. Through macroscopic evaluation, arthritic score was determined at days 13, 18, and 23. Scores 0-4 were given to normal-severe edema and/or erythema in ipsilateral paw. Arthritic score crossing 4 is the indication of involvement of contralateral paw [19].

2.5. Histopathological Examinations of Ankle Joints. The ankle joints of the ipsilateral paw were cut and fixed in $10 \%$ formalin for 36 hours. These separated joints were then submerged in decalcifying solution (a mixture of ethylenediamine tetra acetic acid, sodium tartrate, hydrochloric acid, and potassium sodium tartrate) for 48 hours. Collected tissues were further treated for implanting in paraffin blocks, sliced at $5 \mu \mathrm{m}$ thickness, and stained with hematoxylin and eosin (H\&E). The histopathologist studied the slides in blinded fashion for the detection of bone erosion, inflammation, and pannus formation. A scale (0 to 4$)$ was used for recording results, where 0 represents no pathological change whereas scores 1 to 4 refer to minimal, mild, moderate, and severe changes, respectively $[17,20]$.

2.6. Determination of Inflammatory Cell and Other Hematological Parameters in Blood. At the time of dissection, blood was collected in EDTA containing tubes by intracardiac puncture. Inflammatory cell counts like eosinophils, neutrophils, basophils, and lymphocytes were evaluated in Giemsa Wright stained blood smears under light microscope [21], and counts of RBCs, platelets, and total leukocytes along with $\mathrm{Hb}$ content were determined by using automated hemocytometer. 
2.7. Evaluation of C-Reactive Protein Levels. On day 23, all the rats were sacrificed and blood was withdrawn by intracardiac puncture. Serum was collected after centrifugation for $10 \mathrm{~min}$ at $2380 \mathrm{~g}$. The levels of CPR were determined by agglutination method using commercially available kits (Antec Diagnostic Products, UK). Significant agglutination is observed when high amount of CPR is preset in the serum and it interacts with the antisera. CRP levels were semiquantified according to the kit's protocol [3].

2.8. Determination of Rheumatoid Factor Levels. Rheumatoid factor is the autoantibody produced in arthritis. The level of rheumatoid factor (Rf) was estimated by means of the latex method. The complete procedure was followed according to the manufacturer's guidelines (Approach Bioscience). The concentration of rheumatoid factor was expressed as IU/ml [22].

2.9. Determination of Lysosomal Enzymes and Collagenase Levels. Acid phosphatase analysis was performed by utilizing a substrate known as disodium phenyl phosphate [23]. $\beta$-Glucuronidase was determined by the method of Kawai and Anno [24]. $p$-Nitrophenyl $\beta$-D-glucuronide was used as enzyme substrate in the reaction. $\mathrm{N}$-Acetylglucosaminidase was measured by using the substrate 4-nitrophenyl $\mathrm{N}$-acetylglucosaminide [25]. The activity of $\beta$-galactosidase was assessed by the method of [26] by utilizing the substrate 4-nitrophenyl $N$-acetyl galactopyranoside. Protein concentration was determined as described by [27]. Activity of collagenase was measured by the method of Van and Steinbrink [28], using $N$-(3-[2-furyl] acryloyl)-Leu-Gly-Pro-Ala as substrate.

2.10. Statistical Analysis. The data was analyzed using GraphPad version 5 software. Mean \pm standard deviation was used to represent the data. One-way analysis of variance and post hoc Tukey's test was applied to compare the quantitative variables and to analyze the difference among all groups. $P<0.05$ was considered as statistically significant.

\section{Results}

3.1. A. occidentale Suppressed the Arthritic Development. The results indicated a significantly high arthritic score in arthritic rats as compared to control on day $13(0.00 \pm 0.00$ vs. $3.750 \pm 0.2739)$, day $18(0.00 \pm 0.00$ vs. $4.667 \pm 0.5164)$, and day $23(0.00 \pm 0.00$ vs. $5.000 \pm 0.4472)$. Although treatment with low dose of $A$. occidentale reduced the arthritic score on all these days, this reduction was not statistically significant as compared to the arthritic group. High dose of $A$. occidentale significantly reduced $(p<0.001)$ the arthritic score on day $13(2.333 \pm 0.2582$ vs. $3.750 \pm 0.2739)$, day $18(3.00 \pm 0.3162$ vs. $4.667 \pm 0.5164)$, and day 23 $(2.833 \pm 0.4082$ vs. $5.00 \pm 0.4472)$. Piroxicam also significantly decreased $(p<0.001)$ the arthritic score on these days as compared to the arthritic group $(2.333 \pm 0.4082$ vs. $3.750 \pm 0.2739), \quad(2.833 \pm 0.4082$ vs. $4.667 \pm 0.5164)$, and $(2.750 \pm 0.2739$ vs. $5.000 \pm 0.4472)$, respectively. There was

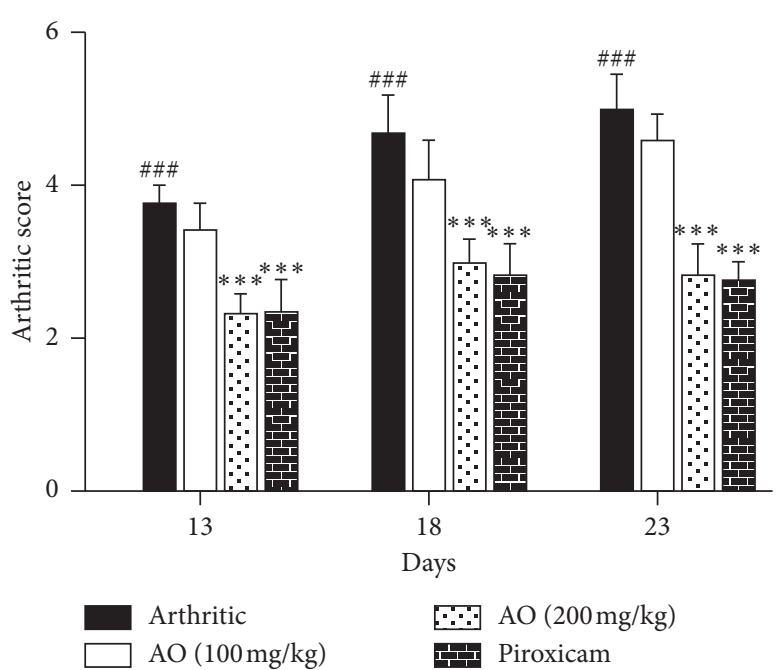

Figure 1: Treatment with $A$. occidentale showed significant reduction in arthritic score. The data is presented as mean \pm SD for $n=6$. \#\#\# $(P<0.001)$ indicating significant difference compared to control group, while ${ }^{* * *}(P<0.001)$ indicates significant difference compared to arthritic group.

no significant difference in the determined arthritic scores in high-dose plant extract-treated group and piroxicam-treated group on all days. The arthritic scores determined at days 13, 18, and 23 are presented Figure 1.

3.2. A. occidentale Significantly Suppressed C-Reactive Protein Levels. Administration of FCA resulted in increased CRP levels of arthritic group as compared to control group $(24.48 \pm 1.362$ vs. $0.00 \pm 0.00)$. Both low- and high-dose treatment of $A$. occidentale showed a significant reduction of CRP levels as compared to arthritic group $(20.08 \pm 1.931$ vs. $24.48 \pm 1.362)$ and $(15.26 \pm 1.727$ vs. $24.48 \pm 1.362)$, respectively. Similarly, piroxicam treatment also significantly decreased the CRP levels as compared to arthritic group $(13.76 \pm 1.172$ vs. $24.48 \pm 1.362)$. On comparing three treatment groups, we found that piroxicam showed a significantly higher capacity to alleviate C-reactive protein levels as compared to the low dose of $A$. occidentale, while no significant difference was seen when compared with the high dose of A. occidentale (Figure 2(a)).

\subsection{A. occidentale Significantly Inhibited Rheumatoid Factor} $(R F)$. Increased levels of RF were found in arthritic group as compared to control group $(119.7 \pm 5.955$ vs. $0.00 \pm 0.00)$. Both high dose of $A$. occidentale and piroxicam showed a significant reduction in RF levels as compared to arthritic group ( $86.00 \pm 4.099$ vs. $119.7 \pm 5.955)$ and $(87.67 \pm 4.546$ vs. $119.7 \pm 5.955)$, respectively. Low dose of $A$. occidentale did not show significant reduction in RF levels compared to arthritic group (112.0 \pm 5.762 vs. $119.7 \pm 5.955)$. We did not find any significant difference between the effect of highdose A. occidentale and piroxicam $(86.00 \pm 4.099$ vs. $119.7 \pm 5.955$ ) (Figure 2(b)). 


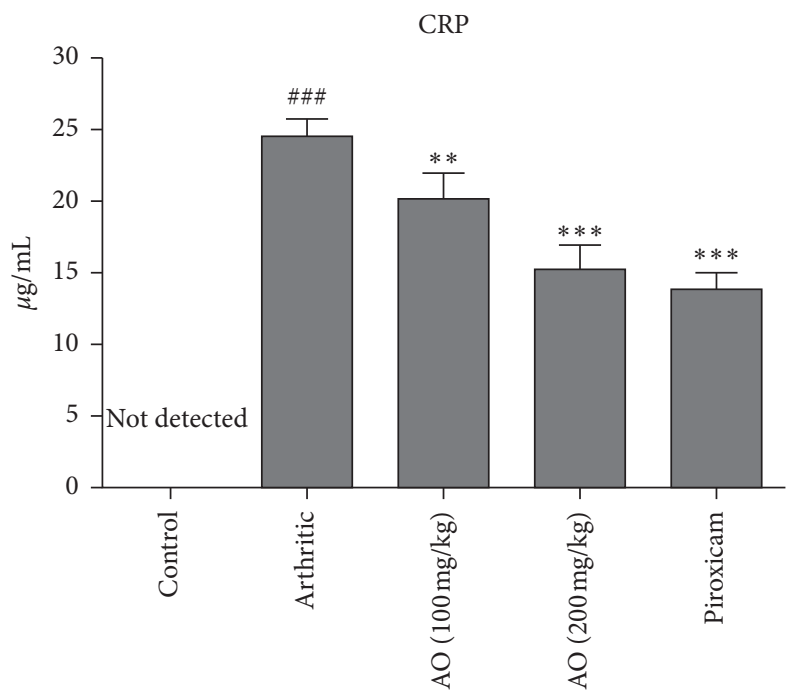

(a)

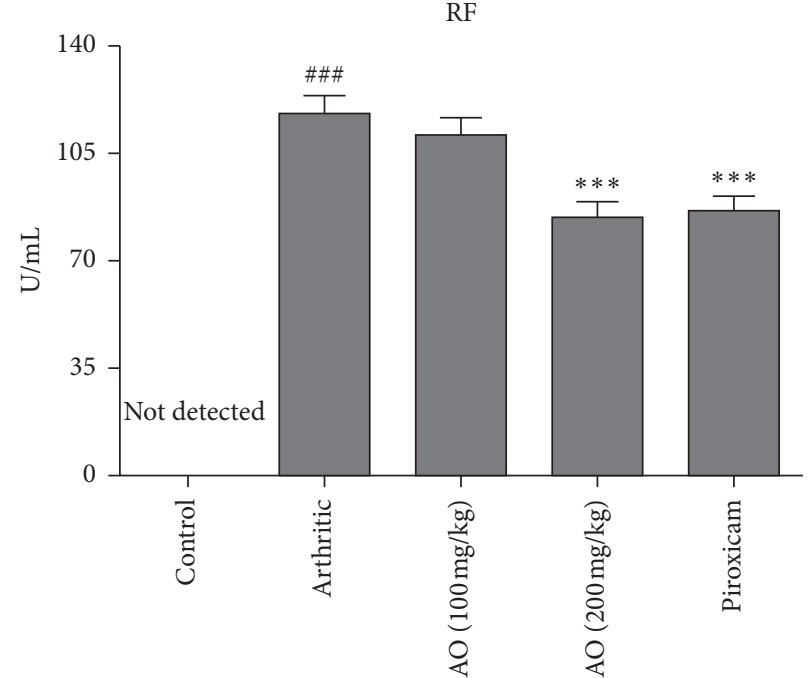

(b)

FIgURE 2: Treatment with A. occidentale extract caused significant suppression of levels of CRP and RF. The data is presented as mean \pm SD for $n=6$. \#\#\# $(P<0.001)$ indicating significant difference compared to control group, while ${ }^{* *}(P<0.01)$ and ${ }^{* * *}(P<0.001)$ indicate significant difference compared to arthritic group.

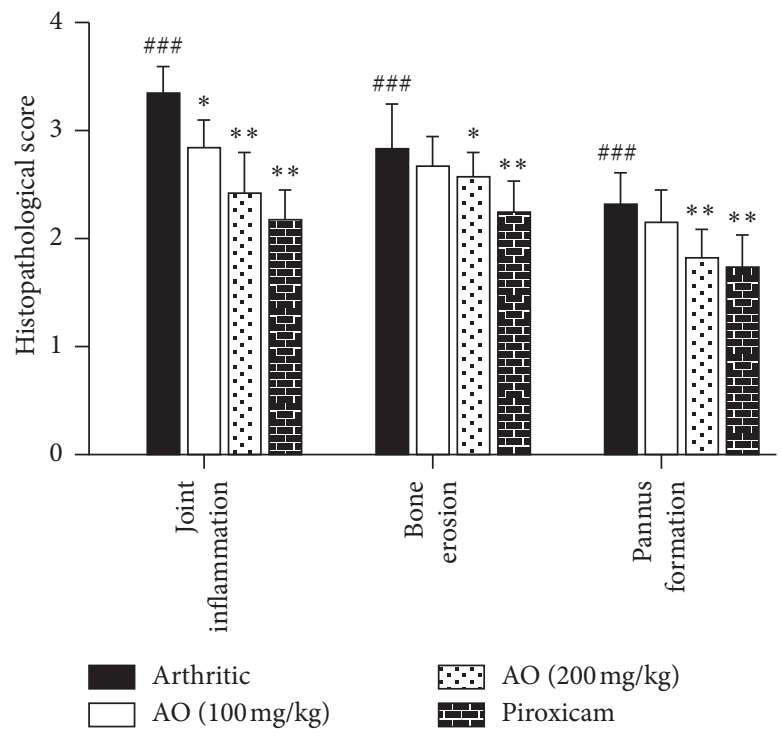

(a)

Figure 3: Continued. 


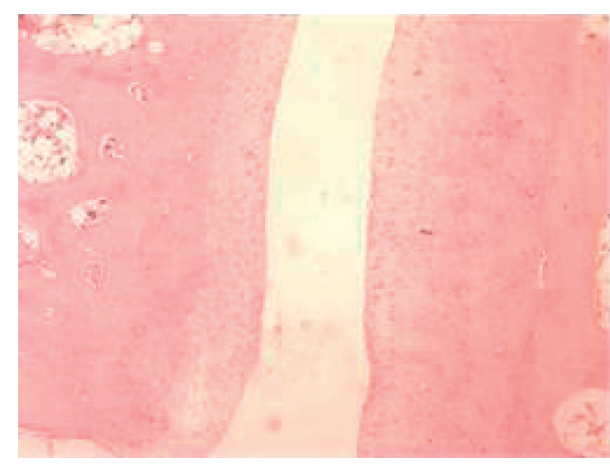

Control

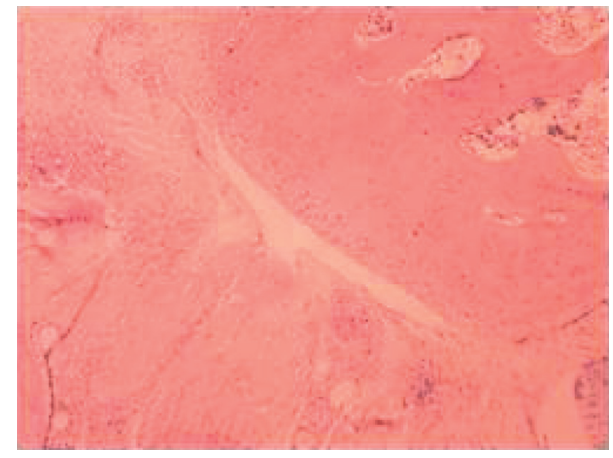

$\mathrm{AO}(100 \mathrm{mg} / \mathrm{kg})$

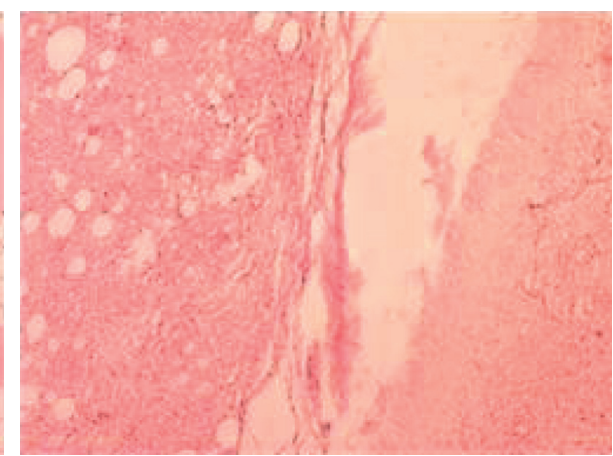

Arthritic

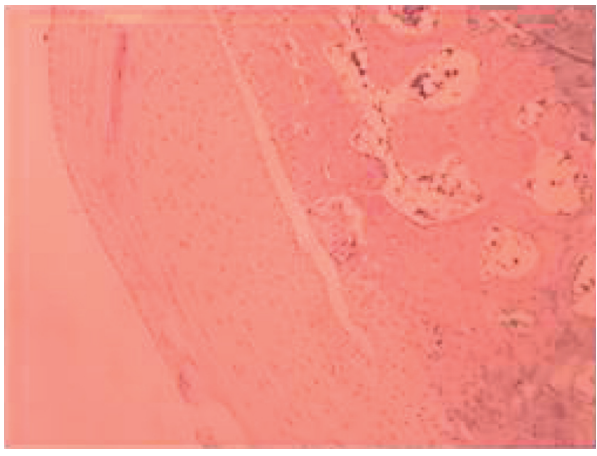

$\mathrm{AO}(200 \mathrm{mg} / \mathrm{kg})$

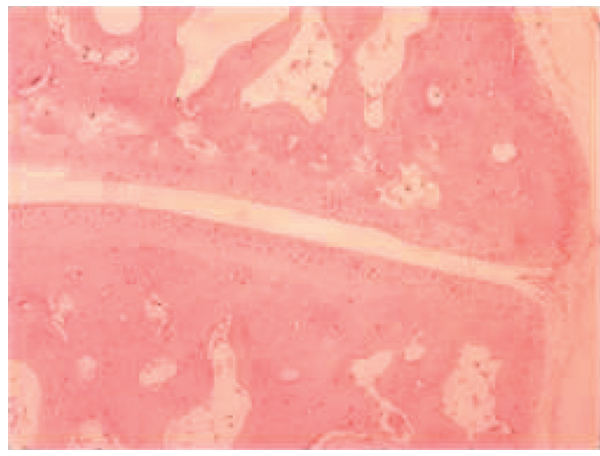

Piroxicam

(b)

FIGURE 3: (a) Treatment with A. occidentale significantly reduced the histopathological score. The data is presented as mean \pm SD for $n=6$. $\# \# \#(P<0.001)$ indicating significant difference compared to control group, while ${ }^{*}(P<0.05),{ }^{* *}(P<0.01)$, and ${ }^{* * *}(P<0.001)$ indicate significant difference compared to arthritic group. (b) H\&E staining, showing normal ankle joint tissue, normal synovium, cartilage, bone, and no inflammation (control group); severe inflammation, pannus, and bony erosion (arthritic group); resolution of inflammation, pannus formation, and bony erosion (low-dose and high-dose AO group); and resolution of inflammation, pannus formation, and bony erosion (piroxicam group).

3.4. Effects of A. occidentale on Histopathological Changes in Ankle Joints. Severe inflammation along with massive joint inflammation, bone erosion, and pannus formation was observed in paw tissue of arthritic rats. Treatment with A. occidentale and piroxicam significantly decreased these histopathological changes (Figures 3(a) and 3(b)).

3.4.1. A. occidentale Significantly Attenuated Joint Inflammation. Significant joint inflammation was observed in arthritic group as compared with control group $(3.333 \pm 0.2582$ vs. $0.0 \pm 0.0)$. Treatment with low dose and high dose of
A. occidentale
$(2.833 \pm 0.2582$ vs. $3.333 \pm 0.2582)$ and
$(2.417 \pm 0.3764$ vs. $3.333 \pm 0.2582$ ) and piroxicam
$(2.167 \pm 0.2582)$ significantly reduced inflammation.

3.4.2. Treatment with A. occidentale Significantly Alleviated Bone Erosion. We observed significantly high bone erosion in arthritic group as compared to control group $(2.833 \pm 0.4082$ vs. $0.0 \pm 0.0)$. Although treatment with low dose of $A$. occidentale decreased the bone erosion, it was not significant $(2.667 \pm 0.2582$ vs. $2.833 \pm 0.4082)$. High-dose A. occidentale and piroxicam significantly reduced the bone 
erosion $(2.583 \pm 0.2041$ vs. $2.833 \pm 0.4082)$ and $(2.250 \pm 0.2739$ vs. $2.833 \pm 0.4082)$, respectively.

3.4.3. A. occidentale Significantly Suppressed Pannus Formation. Results showed increased pannus formation in arthritic group $(2.333 \pm 0.2582)$ as compared to control group. Treatment with low dose of $A$. occidentale did not significantly decrease the pannus formation $(2.167 \pm 0.2582$ vs. $2.333 \pm 0.2582$ ) while high dose of $A$. occidentale and piroxicam significantly reduced the pannus formation as compared to arthritic group (1.833 \pm 0.2582 vs. $2.333 \pm 0.2582)$ and $(1.750 \pm 0.2739$ vs. $2.333 \pm 0.2582)$, respectively.

3.5. A. occidentale Nearly Normalized the Total Leucocyte Count (TLC). The results showed an increase in TLC of arthritic group as compared to control group (9.293 \pm 0.569 vs. $7.305 \pm 0.3885)$ which means FCA-induced arthritis resulted in recruitment of leukocytes in arthritic group. Both low-dose and high-dose treatment of $A$. occidentale showed a significant decrease in TLC as compared to arthritic group $(8.017 \pm 0.3214$ vs. $9.293 \pm 0.569)$ and $(7.900 \pm 0.4801$ vs. $9.293 \pm 0.569)$, respectively. Similarly, piroxicam-treated group also showed a significant decrease in TLC as compared to arthritic group $(7.807 \pm 0.6639$ vs. $9.293 \pm 0.569)$. There was no significant difference in the TLC of low dose, high dose, and piroxicam groups when compared to each other (Table 1).

\subsection{A. occidentale Significantly Suppressed the Raised Levels of DLC}

3.6.1. A. occidentale Significantly Reduced Neutrophil Count. There was a significant increase in neutrophil count of arthritic group as compared to control group (66.78 \pm 2.660 vs. $52.66 \pm 3.369)$. Both low-dose and high-dose treatment of A. occidentale showed a significant decrease in neutrophil count as compared to arthritic group (60.43 \pm 3.972 vs. $66.78 \pm 2.660)$ and $(57.94 \pm 3.052$ vs. $66.78 \pm 2.660)$, respectively. Similarly, piroxicam-treated group also showed a significant decrease in TLC as compared to arthritic group $(54.50 \pm 3.355$ vs. $66.78 \pm 2.660)$. On comparing three treatment groups, we found that piroxicam showed a significantly higher capacity to alleviate neutrophil count as compared to low dose of $A$. occidentale while no significant difference was observed when compared with high dose of A. occidentale (Table 1).

3.6.2. A. occidentale Significantly Reduced the Elevated Lymphocytes Counts. We found a significant increase in lymphocyte counts of arthritic group as compared to control group $(33.66 \pm 0.7083$ vs. $31.18 \pm 0.6081)$ which indicates that FCA-induced arthritis resulted in recruitment of lymphocytes in arthritic group. Low dose of A. occidentale could not significantly reduce the lymphocyte count $(33.27 \pm 1.693$ vs. $33.66 \pm 0.7083)$, while high-dose treatment of $A$. occidentale, as well as piroxicam, showed a significant decrease in lymphocyte count as compared to arthritic group (32.02 \pm 0.5516 vs. $33.66 \pm 0.7083)$ and $(31.96 \pm 0.5322$ vs. $33.66 \pm 0.7083)$, respectively. No significant difference was noted between the effects of high-dose A. occidentale and piroxicam when compared with one another (Table 1$)$.

3.6.3. A. occidentale Ameliorated the Altered Monocyte Counts. A significant increase in monocyte counts of arthritic group was determined as compared to control group (2.412 \pm 0.2001 vs. $1.610 \pm 0.1336)$. Low dose of $A$. occidentale did not significantly reduce the lymphocyte count $(2.303 \pm 0.1720$ vs. $2.412 \pm 0.2001)$, while high-dose treatment of $A$. occidentale, as well as piroxicam, showed a significant decrease in monocyte count as compared to arthritic group $(2.088 \pm 0.1179$ vs. $2.412 \pm 0.2001)$ and $(2.032 \pm 0.1466$ vs. $2.412 \pm 0.2001)$, respectively. No significant difference was found between the effect of high dose A. occidentale and piroxicam when compared with one another (Table 1).

3.6.4. No Significant Change Was Observed in the Counts of Basophils. Results showed no significant change in basophil counts of arthritic group, low-dose A. occidentale, high-dose $A$. occidentale, and piroxicam-treated groups, when compared with each other (Table 1).

3.7. A. occidentale Reduced the Raised Platelet Counts. A significant increase in platelet count of arthritic group was observed as compared to control group (5.567 \pm 0.3259 vs. $4.350 \pm 0.2504)$. Low dose of $A$. occidentale did not significantly affect the platelet count $(5.133 \pm 0.1894$ vs. $5.567 \pm 0.3259)$, while high-dose treatment of $A$. occidentale $(4.908 \pm 0.3642$ vs. $5.567 \pm 0.3259)$, as well as piroxicam $(4.882 \pm 0.1847$ vs. $5.567 \pm 0.3259)$, showed a significant decrease in platelet count as compared to arthritic group. No significant difference was found between the effects of highdose $A$. occidentale and piroxicam when compared with each other (Table 1).

3.8. A. occidentale Significantly Improved the RBC Count. Results indicated a significant decrease in RBC count of arthritic group as compared to control group $(4.163 \pm 0.4052$ vs. $5.827 \pm 0.3257)$. Low dose of $A$. occidentale did not significantly restore the RBC count $(4.450 \pm 0.4241$ vs. $4.163 \pm 0.4052$ ), while high-dose treatment of $A$. occidentale and piroxicam showed a significant increase in RBC count as compared to arthritic group (5.057 \pm 0.3642 vs. $4.163 \pm 0.4052)$ and $(4.963 \pm 0.1445$ vs. $4.163 \pm 0.4052)$, respectively (Table 1 ).

3.9. A. occidentale Restored the Hemoglobin Content. There was a significant decrease in Hb content of arthritic group as compared to control group (11.67 \pm 0.8179 vs. $14.66 \pm 0.3985)$. Low dose and high dose of $A$. occidentale significantly restored the $\mathrm{Hb}$ content as compared to 
TABle 1: Treatment with A. occidentale nearly normalized all the hematological parameters.

\begin{tabular}{|c|c|c|c|c|c|}
\hline \multirow{2}{*}{ Parameters } & \multicolumn{5}{|c|}{ Groups } \\
\hline & Control & Arthritic & $\mathrm{AO}(100 \mathrm{mg} / \mathrm{kg})$ & $\mathrm{AO}(200 \mathrm{mg} / \mathrm{kg})$ & Piroxicam \\
\hline TLC $\left(10^{3}\right)$ & $7.305 \pm 0.388$ & $9.293 \pm 0.569^{\# \# \#}$ & $8.017 \pm 0.321^{* *}$ & $8.017 \pm 0.321^{* * *}$ & $7.807 \pm 0.663^{* * *}$ \\
\hline Neutrophil (\%) & $52.66 \pm 3.369$ & $66.78 \pm 2.660^{\# \# \#}$ & $60.43 \pm 3.972^{*}$ & $57.94 \pm 3.052^{* * *}$ & $54.50 \pm 3.355^{* * *}$ \\
\hline Lymphocytes (\%) & $31.18 \pm 0.608$ & $33.66 \pm 0.708^{\# \# \#}$ & $33.27 \pm 1.693$ & $32.02 \pm 0.551^{*}$ & $31.96 \pm 0.532^{*}$ \\
\hline Monocytes (\%) & $1.610 \pm 0.133$ & $2.412 \pm 0.200^{\# \# \#}$ & $2.303 \pm 0.1720$ & $2.088 \pm 0.117^{*}$ & $2.032 \pm 0.146^{* *}$ \\
\hline Basophils (\%) & $0.8050 \pm 0.034$ & $0.8500 \pm 0.052$ & $0.8400 \pm 0.030$ & $0.8267 \pm 0.043$ & $0.8117 \pm 0.0256$ \\
\hline Platelet count $\left(10^{3}\right)$ & $4.350 \pm 0.250$ & $5.567 \pm 0.325^{\# \# \#}$ & $5.133 \pm 0.189$ & $4.908 \pm 0.364^{* *}$ & $4.882 \pm 0.184^{* *}$ \\
\hline $\operatorname{RBC}\left(10^{6}\right)$ & $5.827 \pm 0.325$ & $4.163 \pm 0.405^{\# \# \#}$ & $4.450 \pm 0.424$ & $5.057 \pm 0.364^{* *}$ & $4.963 \pm 0.144^{* *}$ \\
\hline $\mathrm{Hb}(\mathrm{g} / \mathrm{dL})$ & $14.66 \pm 0.3985$ & $11.67 \pm 0.8179 \# \# \#$ & $12.79 \pm 0.3164^{*}$ & $13.36 \pm 0.4298^{* * *}$ & $13.02 \pm 0.6174^{*}$ \\
\hline
\end{tabular}

arthritic group $(12.79 \pm 0.3164$ vs. $14.66 \pm 0.3985)$ and $(13.36 \pm 0.4298$ vs. $14.66 \pm 0.3985)$, respectively. Similarly, piroxicam also significantly improved the $\mathrm{Hb}$ content $(13.02 \pm 0.6174$ vs. $14.66 \pm 0.398)$. There was no significant difference in the effects of high dose of $A$. occidentale and piroxicam (Table 1).

\subsection{Effects of Anacardium occidentale on Lysosomal Enzymes}

3.10.1. Treatment with A. occidentale Significantly Reduced the Acid Phosphatase Levels. FCA resulted in increased acid phosphatase levels in arthritic group as compared to control group $(0.8450 \pm 0.0432$ vs. $0.2233 \pm 0.0463)$. Both high dose of $A$. occidentale and piroxicam showed a significant reduction in acid phosphatase levels as compared to arthritic group $(0.4300 \pm 0.0540$ vs. $0.845 \pm 0.0432)$ and $(0.3583 \pm$ 0.062 vs. $0.845 \pm 0.043)$, respectively. Low dose of $A$. occidentale did not show any significant reduction in acid phosphatase levels compared to arthritic group $(0.7667 \pm$ 0.043 vs. $0.845 \pm 0.0432$ ). There was no significant difference between the effects of high-dose $A$. occidentale and piroxicam $(0.430 \pm 0.054$ vs. $0.3583 \pm 0.062)$ (Figure $4(\mathrm{a})$ ).

3.10.2. A. occidentale Significantly Suppressed $\beta$-Galactosidase Levels. Elevated levels of $\beta$-galactosidase were found in arthritic group as compared to control group $(3.500 \pm 0.1814$ vs. $1.867 \pm 0.0778)$. Both high dose of $A$. occidentale and piroxicam showed a significant reduction in $\beta$-galactosidase levels as compared to arthritic group (2.542 \pm 0.1532 vs. $3.500 \pm 0.1814)$ and $(2.372 \pm 0.1038$ vs. $3.500 \pm 0.1814)$, respectively. Low dose of $A$. occidentale did not show any significant reduction in $\beta$-galactosidase levels compared to arthritic group $(3.358 \pm 0.1932$ vs. $3.500 \pm 0.1814)$. There was no significant difference between the effect of high-dose A. occidentale and piroxicam $(2.542 \pm 0.1532$ vs. $2.372 \pm 0.1038$ ) (Figure 4(b)).

3.10.3. A. occidentale Significantly Attenuated $\beta$-Glucuronidase Levels. Results indicated high levels of $\beta$-glucuronidase in arthritic group as compared to control group $(5.737 \pm 0.2317$ vs. $2.460 \pm 0.2536)$. Both high dose of A. occidentale and piroxicam treatments resulted in a significant reduction in $\beta$-glucuronidase levels as compared to arthritic group $(2.918 \pm 0.1569$ vs. $5.737 \pm 0.2317)$ and $(3.163 \pm 0.3574$ vs. $5.737 \pm 0.2317)$, respectively. Low dose of A. occidentale showed no significant reduction in $\beta$-glucuronidase levels comparing to arthritic group (5.327 \pm 0.4614 vs. $5.737 \pm 0.2317)$. There was no significant difference between the effect of high-dose $A$. occidentale and piroxicam $(2.918 \pm 0.1569$ vs. $3.163 \pm 0.3574)$ (Figure $4(c))$.

3.10.4. A. occidentale Significantly Alleviated N-Acetyl Glucosaminidase Levels. Arthritic group showed increased levels of $N$-acetyl glucosaminidase as compared to control group $(2.957 \pm 0.0948$ vs. $1.218 \pm 0.0741)$. Both low dose and high dose of $A$. occidentale treatments resulted in a significant reduction in $N$-acetyl glucosaminidase levels as compared to arthritic group $(2.707 \pm 0.2229$ vs. $2.957 \pm$ $0.0948)$ and $(2.047 \pm 0.1211$ vs. $2.957 \pm 0.0948)$, respectively. Piroxicam also significant reduced in $N$-acetyl glucosaminidase levels compared to arthritic group ( $2.257 \pm 0.1618$ vs. $2.957 \pm 0.0948$ ). There was no significant difference between the effect of high-dose $A$. occidentale and piroxicam $(2.047 \pm 0.1211$ vs. $2.257 \pm 0.1618)$ (Figure $4(\mathrm{~d})$ ).

3.10.5. A. occidentale Significantly Decreased Collagenase Levels. Results showed increased levels of collagenase in arthritic group as compared to control group (58.32 \pm 3.308 vs. $31.25 \pm 3.204)$. Both high dose of $A$. occidentale and piroxicam treatments resulted in a significant reduction in collagenase levels as compared to arthritic group $(40.60 \pm 2.109$ vs. $58.32 \pm 3.308)$ and $(41.21 \pm 3.967$ vs. $58.32 \pm 3.308)$, respectively. Low dose of $A$. occidentale showed no significant reduction in collagenase levels compared to arthritic group (52.28 \pm 5.455 vs. $58.32 \pm 3.308)$. There was no significant difference between the effect of high-dose $A$. occidentale and piroxicam (40.60 \pm 2.109 vs. $41.21 \pm 3.967)$ (Figure 5).

\section{Discussion}

Cashew leaves are known for their medicinal properties. The plant is used by the traditional practitioners as anti-inflammatory agent [29]. Various studies using different models of inflammation have validated the anti- 


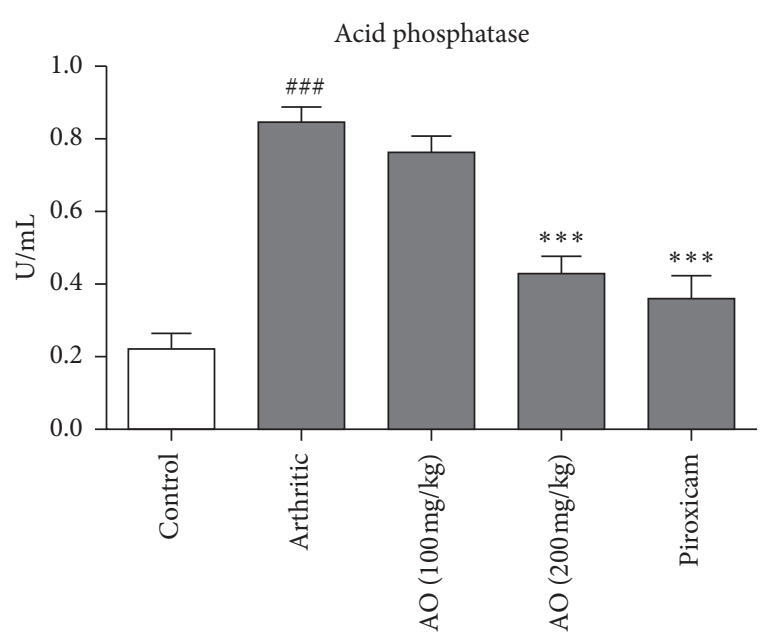

(a)

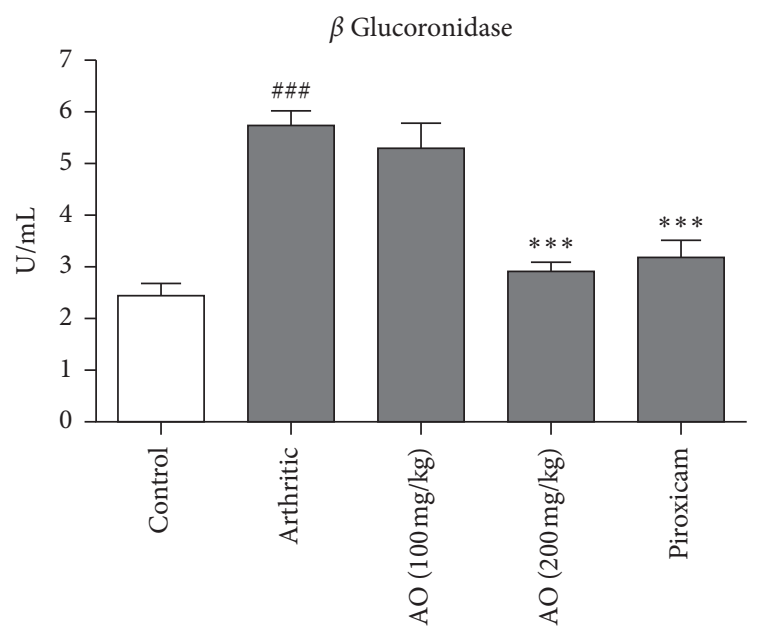

(c)

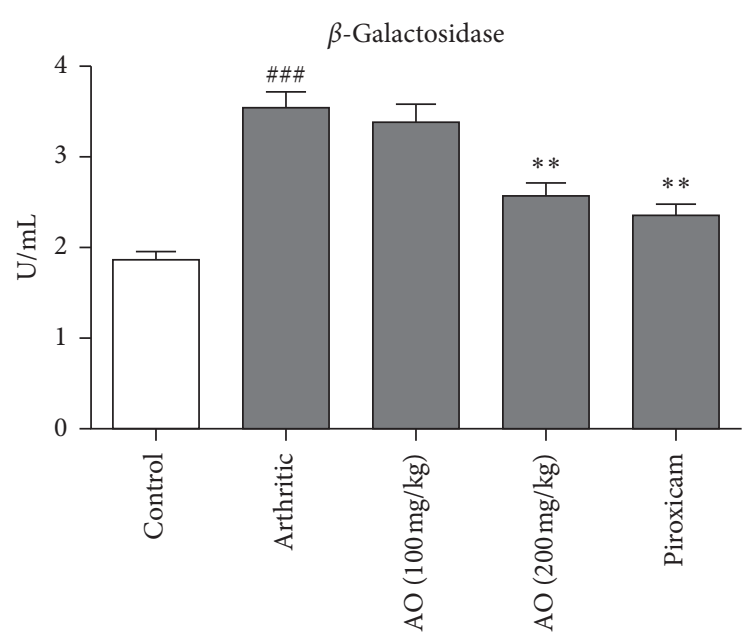

(b)

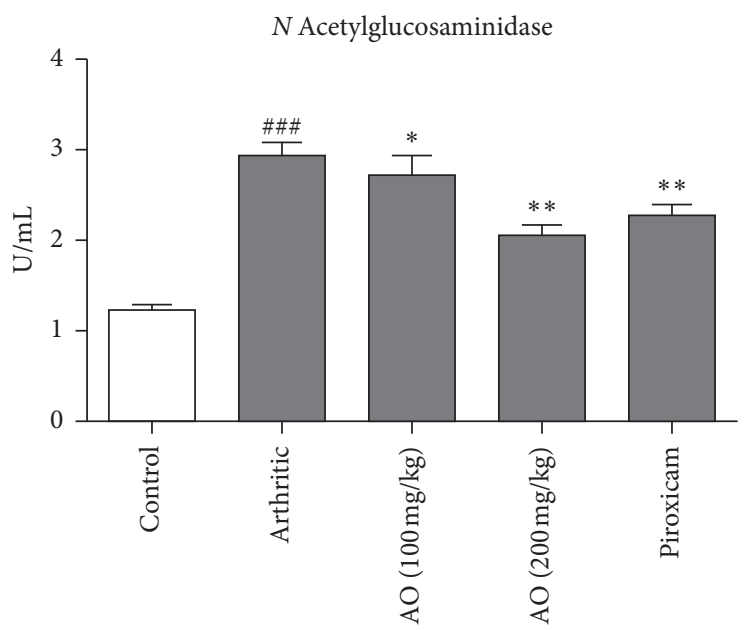

(d)

Figure 4: Treatment with $A$. occidentale leaves extract significantly reduced acid phosphatase, $\beta$-galactosidase, $\beta$-glucuronidase, and $N$-acetylglucosaminidase. The data is presented as mean \pm SD for $n=6$. \#\#\# $(P<0.001)$ indicating significant difference compared to control group, while ${ }^{*}(P<0.05),{ }^{* *}(P<0.01)$, and ${ }^{* * *}(P<0.001)$ indicate significant difference compared to arthritic group.

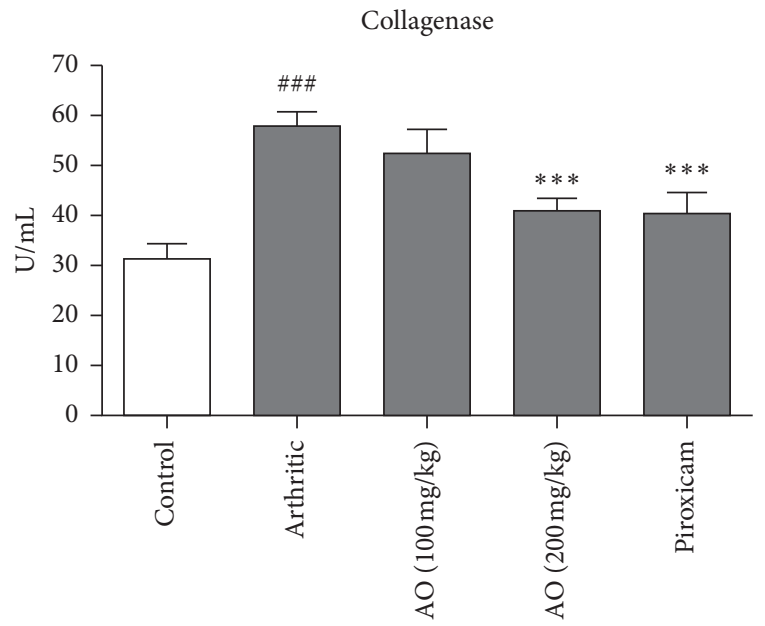

FIGURE 5: Treatment with A. occidentale leaves extract significantly reduced collagenase. The data is presented as mean \pm SD for $n=6$. \#\#\# $(P<0.001)$ indicating significant difference compared to control group, while ${ }^{* * *}(P<0.001)$ indicates significant difference compared to arthritic group. inflammatory properties of cashew $[14,15]$. Current study assessed the antiarthritic effect of cashew leaves extract using FCA-induced arthritic rat model. Adjuvant-induced arthritic model is a well-established model and has been used in several studies to determine the potential therapeutic targets and pathogenesis of RA. The role of inflammatory mediators and serological and pathological changes in adjuvant-induced arthritic model is considered similar to human rheumatoid arthritis [30, 31]. Synovial joints are particularly affected in rheumatoid arthritis. The development of synovial cell hyperplasia, inflammation, bone erosion, and pannus formation are considered as characteristic histopathological features of rheumatoid arthritis [3, 32]. Chronic inflammation of synovial tissues is the major reason for the damage inflicted to bone and cartilage [17]. Current study demonstrated that the treatment with higher dose of A. occidentale significantly attenuated arthritic development, bone erosion, and pannus formation which might be ascribed to anti-inflammatory effects of plant extracts. Reference drug used was piroxicam because it is 
usually prescribed in the treatment of arthritis and is known to ameliorate adjuvant-induced arthritis through its immunomodulatory and anti-inflammatory activities [33, 34].

CRP is known as an acute phase protein and serves as an essential biomarker for different inflammatory, neoplastic, and degenerative disorders. Increased levels of CRP in blood are associated with almost all types of inflammatory disorders, especially in patients suffering from rheumatoid arthritis $[35,36]$. RF is another important biomarker associated with various autoimmune and nonautoimmune diseases, especially rheumatoid arthritis. It is an antibody directed against the antigenic determinants on the Fc region of the immunoglobulin $G$ [37]. RF has long been linked with the pathogenesis of RA and its induction is triggered by the formation of immune complexes during infection [38]. The elevated levels of CRP and RF in arthritic group in present study were found significantly reduced after treatment with both plant extract and piroxicam.

We found increase in TLC and platelet count in arthritic rats as compared with control group. This may be explained as the result of induction of immune response against attacking pathogen. Previous studies using adjuvant-induced arthritic model showed reduction in RBC count and $\mathrm{Hb}$ content in arthritic rats. This decline in hematological markers is an indicative of anemic condition. The anemia may be attributed to different reasons, e.g., failure of iron storage in reticuloendothelial system and synovial tissues and lack of adequate cell production due to failure of bone marrow functioning $[18,39,40]$. Treatment with A. occidentale normalized all the hematological parameters and no significant difference was found between the effects of plant extract and piroxicam.

We also evaluated the potential effects of A. occidentale extract on the levels of different lysosomal enzymes. Lysosomal enzymes have particular importance in rheumatoid arthritis. Lining cells of the synovial membrane and synovial fluid leucocytes were presumed to be the source of the lysosomal enzymes [41]. Acid phosphatase is one of the lysosomal enzymes and is considered responsible for the destruction of cartilage in arthritic condition. Levels of acid phosphatase are increased due to reduced stability of lysosomes in adjuvantinduced arthritis. The enhanced activity of acid phosphatase is an indicative of persistent inflammation [42, 43]. $\beta$-Galactosidase and $\beta$-glucuronidase are other lysosomal enzymes which cleave glycosidic bonds in proteoglycans and glycoproteins resulting in destruction of articular cartilage. A previous study showed that the activities of these exoglycosidase enzymes in both synovial fluid and serum of the arthritic patients were significantly increased [44]. $N$-acetylglucosaminidase is also a marker of inflammation and causes the hydrolysis of $\mathrm{N}$-acetylglucosamine residues from $\mathrm{N}$-acetylglucosaminides [45]. It normally exists in plasma and its levels are found increased in various inflammatory disorders like arthropathies and chronic obstructive pulmonary diseases. In addition, enhanced levels are found in liver disease, diabetes mellitus, and cancer [46]. These results are in accordance with the outcome of this study which also showed enhanced levels of $N$-acetylglucosaminidase, $\beta$-glucuronidase, acid phosphatase, and $\beta$-galactosidase, and in rat serum after induction of arthritis. Treatment with plant extract significantly attenuated the levels of these lysosomal enzymes as compared with arthritic group.

Irreversible joint destruction is a characteristic of RA. Interstitial collagens are present in high content in joints and are critical structural targets of different enzymes. Although the presence of type-I collagen dominates in cartilaginous matrix, type-II collagen is largely found in extracellular matrix of bone, tendons, and ligaments. Collagenase acts by cleaving collagen within triple helical domains, thus playing an important role in RA-associated tissue destruction [47]. We found that treatment with A. occidentale extract significantly reduced collagenase levels as compared with arthritic group. The data showed that the amelioration of FCA-induced arthritis as evidenced by reduction in arthritic score and histopathological score might be attributed to the suppression of various tissue destructive enzyme levels.

A lot of studies have been conducted to evaluate the qualitative and quantitative phytochemical constituents of $A$. occidentale and are summarized in the form of a comprehensive review by [48]. Different vitamins and functional biofactors were reported in the cashew leaves, e.g., vitamin C, vitamins B2 and B3, thiamine, methyl gallute, leucocyanidin, leucodelphinidin, etc. The presence of fatty acids, like $\beta$-sitosterol, stigmasterol, etc., in cashew leaves has also been documented. Various studies revealed the presence of a number of phenolic compounds in the cashew leaves, e.g., 2hydroxy-6-pentadecylbenzoic acid, hyperoside, amentoflavone derivate, myricetin-O-glycoside, kaempferol-3-Oxyloside, quercetin-3-O-xyloside, quercetin-3-O-arabinofuranoside, quercetin-3-O-arabinopyranoside, quercetin-3-Orutinoside, etc. [48]. In another study, fresh cashew leaves were subjected to steam distillation for the evaluation of essential oils and found $\beta$-phellandrene + limonene (17.5\%), methyl chavicol $(11.4 \%)$, germacrene B (8\%), and trans$\alpha$-bergamotene $(7.9 \%)$ in the dominant quantities [49]. Many of these constituents are known to possess anti-inflammatory and antioxidant properties, which might be responsible for the amelioration of rheumatoid arthritis in current study.

\section{Conclusion}

The study suggests that ethanolic extract of leaves of Anacardium occidentale possesses significant antiarthritic properties in rats with FCA-induced arthritis and is attributed to the inhibition of lysosomal enzymes and collagenase. Notably, higher dose of Anacardium occidentale (200 mg/kg b.w.) exhibited better anti-inflammatory effects as compared to low dose (100 mg/kg b.w.).

\section{Abbreviations}

CRP: C-reactive protein

TLC: Total leukocyte count

DLC: Differential leukocyte count 
Rf: Rheumatoid factor

$\mathrm{Hb}$ : Hemoglobin

RBC: Red blood cells

FCA: Freund's complete adjuvant.

\section{Data Availability}

Data are available from the corresponding author upon request.

\section{Conflicts of Interest}

The authors declare that there are no conflicts of interest regarding the publication of this paper.

\section{References}

[1] J. Chang and A. Kavanaugh, "Novel therapies for rheumatoid arthritis," Pathophysiology, vol. 12, no. 3, pp. 217-225, 2005.

[2] R. Khurana and S. M. Berney, "Clinical aspects of rheumatoid arthritis," Pathophysiology, vol. 12, no. 3, pp. 153-165, 2005.

[3] A. Shabbir, M. Shahzad, A. Ali, and M. Zia-Ur-Rehman, "Discovery of new benzothiazine derivative as modulator of pro- and anti-inflammatory cytokines in rheumatoid arthritis," Inflammation, vol. 39, no. 6, pp. 1918-1929, 2016.

[4] J. A. Markenson, "Worldwide trends in the socioeconomic impact and long-term prognosis of rheumatoid arthritis," Seminars in Arthritis and Rheumatism, vol. 21, no. 2, pp. 4-12, 1991.

[5] F. C. Breedveld and J. Kalden, "Appropriate and effective management of rheumatoid arthritis," Annals of the Rheumatic Diseases, vol. 63, no. 6, pp. 627-633, 2004.

[6] B. Combe, "Early rheumatoid arthritis: strategies for prevention and management," Best Practice \& Research Clinical Rheumatology, vol. 21, no. 1, pp. 27-42, 2007.

[7] P. Kumar and S. Banik, "Pharmacotherapy options in rheumatoid arthritis," Clinical Medicine Insights Arthritis Musculoskeletal Disorder, vol. 6, pp. 35-43, 2013.

[8] T. D. Wilsdon and C. L. Hill, "Managing the drug treatment of rheumatoid arthritis," Australian Prescriber, vol. 40, no. 2, pp. 51-58, 2017.

[9] R. Payne, Limitations of NSAIDs for pain management: toxicity or lack of efficacy?, The Journal of Pain, vol. 1, no. 3, pp. 14-18, 2000.

[10] S. H. Venkatesha, R. Rajaiah, B. M. Berman, and K. D. Moudgil, "Immunomodulation of autoimmune arthritis by herbal CAM," Evidence-Based Complementary and Alternative Medicine, vol. 2011, Article ID 986797, 13 pages, 2011.

[11] H. Bliddal, R. Christensen, L. Højgaard et al., "Spiritual healing in the treatment of rheumatoid arthritis: an exploratory single centre, parallel-group, double-blind, three-arm, randomised, sham-controlled trial," Evidence-Based Complementary and Alternative Medicine, vol. 2014, Article ID 269431, 9 pages, 2014.

[12] A. Baptista, R. V. Gonçalves, J. Bressan, and M. C. G. Pelúzio, "Antioxidant and antimicrobial activities of crude extracts and fractions of cashew (Anacardium occidentale L.), cajui (Anacardium microcarpum), and pequi (Caryocar brasiliense C.): a systematic review," Oxidative Medicine and Cellular Longevity, vol. 2018, Article ID 3753562, 13 pages, 2018.

[13] S. A. Onasanwo, T. D. Fabiyi, F. S. Oluwole, and S. B. Olaleye, "Analgesic and anti-inflammatory properties of the leaf extracts of Anacardium occidentalis in the laboratory rodents," Nigerian Journal of Physiological Sciences, vol. 27, no. 1, pp. 65-71, 2012.

[14] F. A. Vanderlinde, H. F. Landim, E. A. Costa et al., "Evaluation of the antinociceptive and anti-inflammatory effects of the acetone extract from Anacardium occidentale L," Brazilian Journal of Pharmaceutical Sciences, vol. 45, no. 3, pp. 437-442, 2009.

[15] O. A. Galdino, M. A. Aderogba, A. D. Adedapo, and J. M. Makinde, "Effects of Anacardium occidentale stem bark extract on in vivo inflammatory models," Journal of Ethnopharmacology, vol. 95, no. 2-3, pp. 139-142, 2004.

[16] O. A. Olajide, M. A. Aderogba, and B. L. Fiebich, "Mechanisms of anti-inflammatory property of Anacardium occidentale stem bark: inhibition of NF- $\kappa$ B and MAPK signalling in the microglia," Journal of Ethnopharmacology, vol. 145, no. 1, pp. 42-49, 2013.

[17] M. Uroos, Z. Abbas, S. Sattar et al., "Nyctanthes arbor-tristis ameliorated FCA-induced experimental arthritis: a comparative study among different extracts," Evidence-Based Complementary and Alternative Medicine, vol. 2017, Article ID 4634853, 13 pages, 2017.

[18] A. Shabbir, M. Shahzad, A. Ali, and M. Zia-ur-Rehman, "Anti-arthritic activity of $\mathrm{N}^{\prime}$-[(2, 4-dihydroxyphenyl)methylidene]-2-(3, 4-dimethyl-5, 5-dioxidopyrazolo[4, 3-c][1, 2] benzothiazin-1(4H)-yl)acetohydrazide," European Journal of Pharmacology, vol. 738, pp. 263-272, 2014.

[19] A. Shabbir, S. A. Batool, M. I. Basheer et al., "Ziziphora clinopodioides ameliorated rheumatoid arthritis and inflammatory paw edema in different models of acute and chronic inflammation," Biomedicine \& Pharmacotherapy, vol. 97, pp. 1710-1721, 2018.

[20] A. M. Uttra, Alamgeer, M. Shahzad, A. Shabbir, and S. Jahan, "Ephedra gerardiana aqueous ethanolic extract and fractions attenuate Freund complete adjuvant induced arthritis in Sprague Dawley rats by downregulating PGE2, COX2, IL- $1 \beta$, IL-6, TNF- $\alpha$, NF- $k$ B and upregulating IL-4 and IL-10," Journal of Ethnopharmacology, vol. 224, pp. 482-496, 2018.

[21] H. Aslam, M. Shahzad, A. Shabbir, and S. Irshad, "Immunomodulatory effect of thymoquinone on atopic dermatitis," Molecular Immunology, vol. 101, pp. 276-283, 2018.

[22] S. Arjumand, M. Shahzad, A. Shabbir, and M. Z. Yousaf, "Thymoquinone attenuates rheumatoid arthritis by downregulating TLR2, TLR4, TNF- $\alpha$, IL-1, and NF- $\kappa$ B expression levels," Biomedicine \& Pharmacotherapy, vol. 111, pp. 958963, 2019.

[23] J. King, "The hydrolases-acid and alkaline phosphatases," in Practical Clinical Enzymology, D. Van, Ed., pp. 191-208, Nostrand Company Limited, London, UK, 1965.

[24] Y. Kawai and K. Anno, "Mucopolysaccharide-degrading enzymes from the liver of the squid, ommastrephes sloani pacificus I. hyaluronidase," Biochimica et Biophysica Acta (BBA)-Enzymology, vol. 242, no. 2, pp. 428-436, 1971.

[25] D. Marhun, "Rapid colorimetric assay of $\beta$-galactosidase and $\mathrm{N}$-acetyl- $\beta$-galactosaminidase in human urine," Clinica Chimica Acta, vol. 73, pp. 453-461, 1976.

[26] P. D. Rosenblit, R. P. Metzger, and A. N. Wick, "Effect of streptozotocin diabetes on acid phosphatase and selected glycosidase activities of serum and various rat organs," $E x$ perimental Biology and Medicine, vol. 145, no. 1, pp. 244-248, 1974.

[27] O. H. Lowry, N. J. Rosebrough, A. L. Farr, and R. J. Randall, "Protein measurement with the folin phenol reagent," The 
Journal of Biological Chemistry, vol. 193, no. 1, pp. 265-275, 1951.

[28] H. E. Van Wart and D. R. Steinbrink, "A continuous spectrophotometric assay for Clostridium histolyticum collagenase," Analytical Biochemistry, vol. 113, no. 2, pp. 356-365, 1981.

[29] T. J. N. Okonkwo, O. Okorie, J. Okonta, and C. Okonkwo, "Sub-chronic hepatotoxicity of Anacardium occidentale (Anacardiaceae) inner stem bark extract in rats," Indian Journal of Pharmaceutical Sciences, vol. 72, no. 3, pp. 353-357, 2010.

[30] P. B. Jacobson, S. J. Morgan, D. M. Wilcox et al., "A new spin on an old model: in vivo evaluation of disease progression by magnetic resonance imaging with respect to standard inflammatory parameters and histopathology in the adjuvant arthritic rat," Arthritis \& Rheumatism, vol. 42, no. 10, pp. 2060-2073, 1999.

[31] Q. Nguyen, J. Shan, L. Di, L. Jiang, and H. Xu, "Therapeutic effects of daphnetin on adjuvant-induced arthritic rats," Journal of Ethnopharmacology, vol. 120, no. 2, pp. 259-263, 2008.

[32] D. M. Polireddy, "Evaluation of anti-arthritic activity of ethanolic extract of sida cardifolia," International Journal of Science and Technology Research, vol. 4, no. 11, pp. 86-96, 2015.

[33] G. Akhtar and A. Shabbir, "Urginea indica attenuated rheumatoid arthritis and inflammatory paw edema in diverse animal models of acute and chronic inflammation," Journal of Ethnopharmacology, vol. 238, Article ID 111864, 2019.

[34] U. H. Hassan, Alamgeer, M. Shahzad et al., "Amelioration of adjuvant induced arthritis in Sprague Dawley rats through modulation of inflammatory mediators by Ribes alpestre Decne," Journal of Ethnopharmacology, vol. 235, pp. 460-471, 2019.

[35] M. B. Pepys and G. M. Hirschfield, "C-reactive protein: a critical update," Journal of Clinical Investigation, vol. 111, no. 12, pp. 1805-1812, 2003.

[36] G. Sindhu, M. Ratheesh, G. L. Shyni, B. Nambisan, and A. Helen, "Anti-inflammatory and antioxidative effects of mucilage of Trigonella foenum graecum (Fenugreek) on adjuvant induced arthritic rats," International Immunopharmacology, vol. 12, no. 1, pp. 205-211, 2012.

[37] F. Ingegnoli, R. Castelli, and R. Gualtierotti, "Rheumatoid factors: clinical applications,” Disease Markers, vol. 35, no. 5, pp. 727-734, 2013.

[38] I. B. McInnes and G. Schett, "The pathogenesis of rheumatoid arthritis," New England Journal of Medicine, vol. 365, no. 23, pp. 2205-2219, 2011.

[39] A. G. Mowat, "Hematologic abnormalities in rheumatoid arthritis," Seminars Arthritis and Rheumatism, vol. 1, no. 3, pp. 195-219, 1971.

[40] S. Ekambaram, S. S. Perumal, and V. Subramanian, "Evaluation of anti-arthritic activity of Strychnos potatorum Linn seeds in Freund's adjuvant induced arthritic rat model," BMC Complementary Alternative Medicine, vol. 10, p. 56, 2010.

[41] K. D. Muirden, "Lysosomal enzymes in synovial membrane in rheumatoid arthritis. Relationship to joint damage," Annals of the Rheumatic Diseases, vol. 31, no. 4, pp. 265-271, 1972.

[42] I. Olsen, S. Bon-Gharios, and D. Abraham, "The activation of resting lymphocytes is accompanied by the biogenesis of lysosomal organnels," European Journal of Immunology, vol. 20, pp. 2161-2170, 1990.

[43] N. K. Mishra, S. Bstia, G. Mishra, K. A. Chowdary, and S. Patra, "Anti-arthritic activity of Glycyrrhiza glabra,
Boswellia serrata and their synergistic activity in combined formulation studied in Freund's adjuvant induced arthritic rats," Journal of Pharmaceutical Education and Research, vol. 2, no. 2, pp. 92-98, 2011.

[44] S. Pancewicz, J. Popko, R. Rutkowski et al., "Activity of lysosomal exoglycosidases in serum and synovial fluid in patients with chronic Lyme and rheumatoid arthritis," Scandinavian Journal of Infectious Diseases, vol. 41, no. 8, pp. 584-589, 2009.

[45] M. Knaś, E. Albera, and M. Różańska-Boczula, "Activities of $\mathrm{N}$-acetyl- $\beta$-d-glucosaminidase and glutathione peroxidase in bovine colostrum and milk," Czech Journal of Animal Science, vol. 55, no. 11, pp. 488-495, 2010.

[46] M. P. Iqbal, K. A. Kazmi, H. R. Jafri, and N. Mehboobali, "NAcetyl- $\beta$-D-glucosaminidase in acute myocardial infarction," Experimental \& Molecular Medicine, vol. 35, no. 4, pp. 275278, 2003.

[47] F. Sabeh, D. Fox, and S. J. Weiss, "Membrane-type I matrix metalloproteinase-dependent regulation of rheumatoid arthritis synoviocyte function," The Journal of Immunology, vol. 184, no. 11, pp. 6396-6406, 2010.

[48] B. Salehi, M. Gültekin-Özgüven, C Kırkın et al., "Anacardium plants: chemical, Nutritional composition and biotechnological applications," Biomolecules, vol. 9, no. 9, p. 465, 2019.

[49] C. Silva, M. Moudachirou, V. Adjakidje, J.-C. Chalchat, and G. Figuérédo, "Essential oil chemical composition of anacardium occidentaleL. leaves from Benin," Journal of Essential Oil Research, vol. 20, no. 1, pp. 5-8, 2008. 